\title{
PRODUÇÃO DE MELÃO SOB DUAS DENSIDADES DE PLANTIO, EM DIFERENTES TIPOS E ESPAÇAMENTOS DE GOTEJADORES ${ }^{1}$
}

\author{
Nildo da Silva Dias ${ }^{2}$, José Francismar de Medeiros $^{3} \&$ Nilson de Sousa Sathler ${ }^{4}$
}

\begin{abstract}
RESUMO
Com o objetivo de se avaliar o efeito de diferentes tipos e espaçamentos de gotejadores usados no cultivo de melão sob duas densidades de plantio, desenvolveu-se um experimento na Fazenda São João, Município de Mossoró, RN, durante o período de setembro a novembro de 1998. O delineamento experimental utilizado foi o de blocos casualizados completos, em parcelas subdivididas, com três repetições. Nas parcelas experimentais foram instaladas as diferentes linhas de gotejadores (Katif 2,3 $\mathrm{L} \mathrm{h}^{-1}$ a 0,40 e 0,60 m; Katif 3,75 $\mathrm{L} \mathrm{h}^{-1}$ a 0,60 e 0,80 m; Hydrodrip II 2,3 $\mathrm{L} \mathrm{h}^{-1}$ a 0,30 e 0,50 m;

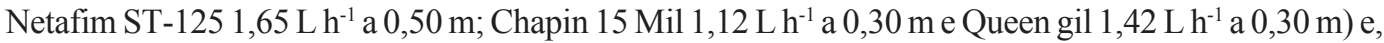
nas subparcelas, as populações de 15.000 e 20.000 plantas ha $^{-1}$. Os resultados mostraram que o uso de gotejadores de menor espaçamento ou maior vazão com a maior densidade de plantio, proporcionou maior porcentagem do stand de plantas de melão. Maiores rendimentos de melão foram obtidos quando se utilizaram as linhas de gotejadores Queen gil 1,42 L h $\mathrm{h}^{-1}$ a $0,30 \mathrm{~m}$ e Hydrodrip II 2,3 $\mathrm{L} \mathrm{h}^{-1}$ a

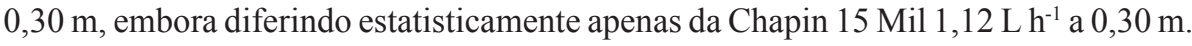

Palavras-chave: irrigação por gotejamento, manejo de água, Cucumis melo L.

\section{PRODUCTION OF MELON UNDER TWO PLANT DENSITIES IN DIFFERENT SPACINGS AND KINDS OF DRIPPERS}

\begin{abstract}
To evaluate the effect of different kinds and dripper spacings used in the melon cultivation, under two plant densities, a study was conducted at 'São João' farm, in the municipal district of Mossoró, RN, during the period of September to November, 1998. The experimental design was a completely randomized block in a split-plot layout, with three replications. The different dripper lines were installed in main plots (Katif 2.3 $\mathrm{L} \mathrm{h}^{-1}$ at 0.40 and $0.60 \mathrm{~m}$; Katif $3.75 \mathrm{~L} \mathrm{~h}^{-1}$ at 0.60 and $0.80 \mathrm{~m}$; Hydrodrip II

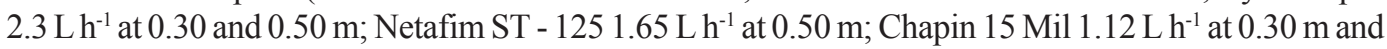
Queen gil $1.42 \mathrm{~L} \mathrm{~h}^{-1}$ at $0.30 \mathrm{~m}$ ) and, in subplots, the populations of 15,000 and 20,000 plants ha ${ }^{-1}$. The results showed that the stand percentage was higher in the dripper of smaller spacing and discharge and for higher plant density. The dripper lines Queen gil $1.42 \mathrm{~L} \mathrm{~h}^{-1}$ at $0.30 \mathrm{~m}$ and Hydrodrip II $2.3 \mathrm{~L} \mathrm{~h}^{-1}$ at

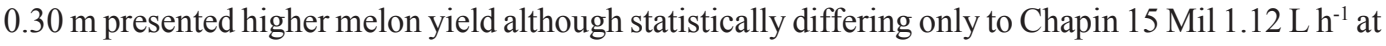
$0.30 \mathrm{~m}$.
\end{abstract}

Key words: trickle irrigation, water management, Cucumis melo L.

Recebido em 17/04/2000, Protocolo 042/00

${ }^{1}$ Parte da Monografia de Graduação apresentada pelo primeiro autor à Escola Superior de Agricultura de Mossoró, ESAM

${ }^{2}$ Eng Agrônomo, Pós-graduando em Engenharia Agrícola, UFPB, CP 10.078, CEP 58109 - 970, Campina Grande, PB. E-mail: nsdias@deag.ufpb.br

${ }^{3}$ Eng Agrônomo, Dr., Prof. do Departamento de Engenharia -ESAM, CEP 59625 - 900, Mossoró, RN. Fone: (0xx84) 312 2100, Fax: (0xx84) 312 2499.E mail: jfmedeir@esam.br

${ }^{4}$ Eng. Agrônomo, M.Sc., Prof. Adjunto do Departamento de Engenharia - ESAM. Fone: (0xx84) 312 1680, Email: sathler@esam.br 


\section{INTRODUÇÃO}

O melão é, provavelmente, uma das espécies olerícolas de maior expressão econômica e social para o Estado do Rio Grande do Norte. $\mathrm{O}$ aumento da produtividade e a qualidade das frutas podem ser alcançados por diferentes formas, entre as quais se destacam o uso de sistemas de irrigação localizada com elevados níveis de eficiência e, aliados a um redução de custos de produção pela economia de água, energia, fertilizantes e mão-de-obra (Bernardo, 1995).

A economia de água alcançada mediante a irrigação por gotejamento é considerável. Segundo Vermeiren \& Jobling (1986) este sistema economiza, em geral, entre 20 a 30\% de água a mais que os sistemas de irrigação por aspersão.

Em virtude da potencialidade deste método, tem sido crescente a demanda por este tipo de irrigação, principalmente para frutíferas, o que tem acarretado o surgimento, no mercado, de vários equipamentos para irrigação por gotejamento. Para Gomes (1999) a variedade de gotejadores existente no mercado é muito grande devido, principalmente, ao objetivo permanente que os fabricantes almejam: gotejadores eficazes, resistentes e baratos.

No sistema de irrigação localizada, a obtenção de elevadas uniformidade e eficiência de aplicação de água, fatores importantes no rendimento das culturas, depende, como em nenhum outro sistema, da qualidade de seus componentes. A variação de fabricação do gotejador é um importante fator que influencia na uniformidade de distribuição de água de um sistema de irrigação por gotejamento, cujos formato, materiais usados em sua construção e o cuidado com que é fabricado, determinam a qualidade de variação esperada de qualquer modelo de gotejador, fazendo-se necessário realizar-se testes para verificar seu desempenho, sobretudo em nível de campo (Scaloppi, 1986). Portanto, dois gotejadores retirados de um mesmo lote, testados a pressão e temperatura constantes, poderão ter diferentes vazões. Esta diferença variará de um modelo para outro, dependendo do projeto do gotejador, dos materiais usados em sua construção e do controle de qualidade com o que é fabricado.

Por outro lado, o aumento do rendimento da cultura pode ser obtido através de elevação da densidade de plantio, desde que não haja diminuição muito acentuada do peso médio nem da qualidade dos frutos (Bezerra, 1981). Para Robinson \& Decker-Walteres (1997) a maior vantagem dos plantios mais adensados é o ganho de produtividade com menor custo de produção, pela utilização mais eficiente da radiação solar, da água e dos nutrientes e, possivelmente, pelo melhor controle natural das plantas invasoras e de algumas pragas e doenças.

Em melão, as altas densidades produzem um grande número de frutos por área, mas com tamanho, peso e número de frutos por planta reduzidos. Tal fato, segundo Janick (1968) tem sido atribuído principalmente às pressões de competição inter e intraplanta e, neste caso, a causa do incremento no rendimento do melão é o aumento da densidade visto que, mesmo se criando condições para uma competição menor entre as plantas, o seu maior rendimento será incrementado pelo maior número de plantas por área.

Segundo Pedrosa (1997) a densidade de plantio em melão varia em função do nível tecnológico empregado e da finalidade do produto (fruto para o mercado interno ou externo) sendo que no Rio Grande do Norte o espaçamento adotado pelos produtores, conforme Almeida (1992) é 2,0 a 2,5 m entre fileiras e de 0,3 a $1,0 \mathrm{~m}$ entre plantas, deixando-se 1 ou 2 plantas por cova (4.000 a 30.000 plantas ha $^{-1}$ ).

Atualmente, o espaçamento mais utilizado, principalmente pelas grandes empresas, tem sido o de $2,0 \times 0,5 \mathrm{~m}$ com duas plantas por cova (20.000 plantas ha $\left.{ }^{-1}\right)$, entretanto, em função da textura do solo e da vazão do gotejador, existe um espaçamento de emissor adequado capaz de molhar uma faixa contínua de solo, o que possibilita semear-se a espaçamentos independentes da distância entre os gotejadores na linha, permitindo uma possível semeadura mecanizada. Para Dasberg \& Bresler (1985) a condutividade hidráulica do solo é a principal propriedade do solo, que determina o espaçamento entre gotejadores, a qual, juntamente com a vazão do emissor, determina a área do bulbo molhado na zona radicular

Levando-se em consideração esses aspectos, objetivou-se avaliar os diferentes tipos e espaçamento de gotejadores na produção do melão, em duas densidades de plantio e semeado em faixa contínua.

\section{MATERIAL E MÉTODOS}

$\mathrm{O}$ experimento foi desenvolvido na área experimental da Fazenda São João Ltda., localizada no km 4 da RN-15, no Município de Mossoró, RN, no período de 20 de setembro a 28 de novembro de 1998. Mossoró está situada na latitude $5^{\circ} 11^{\prime} \mathrm{S}$, longitude $37^{\circ} 20^{\prime} \mathrm{W}$ Gr., com altitude $18 \mathrm{~m}$ e, segundo a classificação de Köppen, possui clima do tipo BSwh', isto é, seco, muito quente e com estação chuvosa no verão, atrasandose para o outono.

O solo foi classificado como Podzólico Vermelho-Amarelo Eutrófico, textura média fase caatinga hiperxerófila e relevo plano (SUDENE, 1968). As características físico-hídricas do solo da área experimental são apresentadas na Tabela 1.

Tabela 1. Características físico-hídricas do solo da área experimental (Ferreira, 1995)

\begin{tabular}{lccc}
\hline Características Físico-Hídricas & \multicolumn{3}{c}{ Profundidade $(\mathrm{cm})$} \\
\hline Granulometria $\left(\mathrm{g} \mathrm{kg}^{-1}\right)$ & $0-15$ & $15-35$ & $35-84$ \\
\cline { 2 - 4 } Areia & 548 & 549 & 478 \\
Silte & 101 & 102 & 101 \\
Argila & 351 & 349 & 421 \\
\hline Densidade $\left(\mathrm{kg} \mathrm{dm}^{-3}\right)$ & & & \\
Global & 1,67 & 1,63 & 1,59 \\
Partícula & 2,50 & 2,52 & 2,52 \\
\hline Umidade $\left(\mathrm{cm}^{3} \mathrm{~cm}^{-3}\right)$ & & & \\
$0,01 \mathrm{MPa}$ & 32,94 & 31,25 & 29,90 \\
$1,50 \mathrm{MPa}$ & 16,21 & 15,71 & 16,50 \\
\hline
\end{tabular}

As condições médias da temperatura diária, da umidade relativa e da velocidade do vento durante o experimento, foram de $28,39^{\circ} \mathrm{C}, 63,09 \%$ e $5,04 \mathrm{~m} \mathrm{~s}^{-1}$, respectivamente, medidas a 12 km da Fazenda São João, na Estação Meteorológica da Escola Superior de Agricultura de Mossoró - ESAM.

A água de irrigação utilizada apresentava as seguintes características: $\mathrm{CE}=0,55 \mathrm{dS} \mathrm{m}^{-1} ; \mathrm{pH}=8,0 ; \mathrm{Na}=2,78$ mmol $_{\mathrm{c}} \mathrm{L}^{-1}$; 
$\mathrm{Ca}=2,0 \mathrm{mmol}_{\mathrm{c}} \mathrm{L}^{-1} ; \mathrm{Mg}=0,9 \mathrm{mmol}_{\mathrm{c}} \mathrm{L}^{-1} ; \mathrm{K}=0,4 \mathrm{mmol}_{\mathrm{c}} \mathrm{L}^{-1}$; $\mathrm{Cl}=1,8 \mathrm{mmol}_{\mathrm{c}} \mathrm{L}^{-1}, \mathrm{HCO}_{3}=4,0 \mathrm{mmol}_{\mathrm{c}}^{\mathrm{c}} \mathrm{L}^{-1} \mathrm{eCO}_{3}=0,2 \mathrm{mmol}_{\mathrm{c}}^{\mathrm{L}} \mathrm{L}^{-1}$.

O delineamento experimental foi o de blocos casualizados completos em parcelas subdivididas com três repetições. Nas parcelas experimentais foram instaladas as diferentes linhas de gotejadores (L) e, nas subparcelas, as densidades de plantio (D). Linhas de gotejadores: $\mathrm{L}_{1}=$ Katif $3,75 \mathrm{~L} \mathrm{~h}^{-1}$ a $0,80 \mathrm{~m}$; $\mathrm{L}_{2}=$ Katif $3,75 \mathrm{~L} \mathrm{~h}^{-1}$ a $0,60 \mathrm{~m} ; \mathrm{L}_{3}=$ Katif $2,3 \mathrm{Lh}^{-1}$ a $0,60 \mathrm{~m}$; $\mathrm{L}_{4}=$ Katif $2,3 \mathrm{~L} \mathrm{~h}^{-1}$ a $0,40 \mathrm{~m} ; \mathrm{L}_{5}=$ Hydrodrip II $2,3 \mathrm{~L} \mathrm{~h}^{-1}$ a $0,50 \mathrm{~m}$; $\mathrm{L}_{6}=$ Hydrodrip II 2,3 $\mathrm{L} \mathrm{h}^{-1}$ a $0,30 \mathrm{~m} ; \mathrm{L}_{7}=$ Netafim ST-125 1,65 $\mathrm{L} \mathrm{h}^{-}$ ${ }^{1}$ a $0,50 \mathrm{~m} ; \mathrm{L}_{8}=$ Chapin $15 \mathrm{Mil} 1,12 \mathrm{~L} \mathrm{~h}^{-1}$ a $0,30 \mathrm{~m} \mathrm{e}_{9}=$ Queen gil $1,42 \mathrm{~L} \mathrm{~h}^{-1}$ a $0,30 \mathrm{~m}$. Densidade de plantio: $\mathrm{D}_{1}=15000$ plantas ha- ${ }^{-1}$, correspondendo ao espaçamento de $2,00 \times 0,33 \mathrm{~m}$ e $\mathrm{D}_{2}=20000$ plantas $\mathrm{ha}^{-1}$, referente ao espaçamento de $2,00 \mathrm{x}$ $0,25 \mathrm{~m}$. Cada subparcela correspondeu a uma fileira de plantas de $15 \mathrm{~m}$ de comprimento, sendo $1,0 \mathrm{~m}$ de cada extremidade considerada como bordadura.

A cultura utilizada foi o melão valenciano (Cucumis melo L.), cultivar Gold Mine, conhecido como meloeiro, originário dos continentes Asiático e Africano. É um híbrido muito produtivo, menos exigente em água e tem apresentado boa tolerância de campo a oídio e míldio; os frutos são uniformes, com peso médio em torno de $1,90 \mathrm{~kg}$, pequena cavidade interna, sem odor e de coloração branco-creme (Pedrosa, 1997).

Com o solo a capacidade de campo, fez-se a semeadura em faixa contínua, ou seja, não se levou em consideração o espaçamento entre os gotejadores, enquanto o suprimento hídrico foi executado de acordo com o cronograma da empresa, obedecendo-se aos estádios de desenvolvimento da cultura, num volume total médio de $3380 \mathrm{~m}^{3} \mathrm{ha}^{-1}(338 \mathrm{~mm})$ por cada tratamento. Foram instaladas válvulas individuais no início de cada parcela experimental (linhas de gotejadores) para controlar o volume de água aplicado.

As adubações foram realizadas diariamente em fertirrigação, seguindo-se o cronograma da empresa e a necessidade da cultura, cujas quantidades totais utilizadas até o final do ciclo, $\mathrm{em} \mathrm{kg} \mathrm{ha-1}$, foram as seguintes: nitrogênio $=130$; fósforo $=199$ e potássio $=243$, nas formas de nitrato de amônio e uréia, ácido fosfórico e sulfato de potássio, respectivamente, enquanto o controle fitossanitário e as capinas foram realizados de acordo com a necessidade, seguindo-se os critérios adotados para o plantio comercial da Fazenda.

Realizou-se o levantamento do stand aos 20 dias após a semeadura, pela contagem das plantas existentes em cada subparcela e relacionadas à quantidade máxima esperada (correção do "stand" de plantas). Efetuaram-se três colheitas, a primeira 62 dias após o plantio e as outras em intervalo de 4 dias.

As características avaliadas foram: crescimento de plantas, medindo-se o comprimento transversal de ramos em relação à linha de semeadura, e número de frutos por planta, obtido pela contagem do número total na área útil da subparcela dividido pelo número de plantas. Determinaram-se, também, os pesos médios dos frutos comerciais e totais, e a produção comercial e total, através da pesagem de todos os frutos da área útil, estimada em $\mathrm{Mg} \mathrm{ha}^{-1}$. Os frutos foram classificados de acordo com o tipo, padronizados pela Empresa para mercado nacional e exportação, considerando-se comerciais os frutos livres de danos mecânicos, manchas e deformações. Além disso, os teores de sólidos solúveis totais ( ${ }^{\circ}$ Brix) foram determinados com refratômetro digital, com compensação de temperatura automática. As amostras foram obtidas pela retirada de uma fatia do fruto, cortado longitudinalmente, seguida da homogeneização da polpa em um liquidificador industrial e, também, através da retirada de algumas gotas diretamente da região equatorial do fruto, em uma fatia longitudinal, expressando-se os resultados em porcentagem. A textura dos frutos foi determinada dividindo-se longitudinalmente em quatro partes, sendo que em cada uma delas procedeu-se a uma leitura (em regiões diferentes) com penetrômetro com "pluger" de $8 \mathrm{~mm}$ de diâmetro, cujos resultados médios foram expressos em newton $(\mathrm{N})$.

A análise estatística constou da análise de variância e as médias foram comparadas pelo teste de Tukey ou "t", a 5\% de probabilidade (Gomes, 1987).

\section{RESULTADOS E DISCUSSÃO}

A maior porcentagem do stand foi obtida para a linha de gotejadores de menor espaçamento ou maior vazão e com a maior densidade de plantio (Tabela 2). Os gotejadores de maior espaçamento, sobretudo os de menor vazão, não proporcionaram molhamento da faixa contínua superficial do solo no início do cultivo, onde é posta a semente e, em linhas com menor espaçamento entre gotejadores, embora podendo ter vazão unitária menor, obtiveram-se maiores porcentagens do stand, fato que se deve principalmente a uma maior distribuição de vazão nessas linhas, quando comparadas com as de gotejadores com espaçamento maior, além do reduzido espaçamento possibilitar maior quantidade de sementes próximo ao gotejador.

O crescimento do melão nas diferentes linhas de gotejadores, aos 38 dias de semeadura refletiu, de certa forma, na produção final da cultura, embora não diferindo mais a partir do $45^{\circ}$ dia, fato decisivo na produção total do melão, pois a $\mathrm{L}_{8}$, que indicou menor crescimento aos 38 dias apresentou, também, menor produção total média de melão. Aos 38 dias do plantio a largura de faixa coberta pela cultura mostrou maior variação entre as linhas de gotejadores, caso em que as linhas Katif $3,75 \mathrm{~L} \mathrm{~h}^{-1}$ a $0,60 \mathrm{~m}\left(\mathrm{~L}_{2}\right)$, que não diferiram da Katif $3,75 \mathrm{~L} \mathrm{~h}^{-1}$ a $0,80 \mathrm{~m}\left(\mathrm{~L}_{1}\right) \mathrm{e}$

Tabela 2. Porcentagem do stand populacional aos 20 dias após a semeadura para as diferentes linhas de gotejadores e densidades de plantio

\begin{tabular}{ccccccccccc}
\hline \multirow{2}{*}{ População } & \multicolumn{10}{c}{ Linha de Gotejadores* } \\
\cline { 2 - 11 } & \multicolumn{1}{c}{$\mathrm{L}_{1}$} & $\mathrm{~L}_{2}$ & $\mathrm{~L}_{3}$ & $\mathrm{~L}_{4}$ & $\mathrm{~L}_{5}$ & $\mathrm{~L}_{6}$ & $\mathrm{~L}_{7}$ & $\mathrm{~L}_{8}$ & $\mathrm{~L}_{9}$ & $\mathrm{Média}$ \\
\hline 15000 & $81,83 \mathrm{~A}$ & $82,93 \mathrm{~A}$ & $83,33 \mathrm{~A}$ & $69,23 \mathrm{~B}$ & $76,63 \mathrm{~A}$ & $76,93 \mathrm{~A}$ & $63,63 \mathrm{~A}$ & $82,60 \mathrm{~A}$ & $92,45 \mathrm{~A}$ & 78,73 \\
20000 & $88,53 \mathrm{~A}$ & $88,50 \mathrm{~A}$ & $71,69 \mathrm{~B}$ & $83,90 \mathrm{~A}$ & $84,47 \mathrm{~A}$ & $96,57 \mathrm{~B}$ & $69,13 \mathrm{~A}$ & $91,77 \mathrm{~A}$ & $97,67 \mathrm{~A}$ & 85,80 \\
\hline Média & 85,18 & 85,72 & 77,50 & 76,57 & 80,55 & 86,75 & 66,38 & 87,18 & 94,95 & \\
\hline
\end{tabular}

* Médias seguidas pela mesma letra maiúscula nas colunas não diferem, a $5 \%$ de probabilidade, pelo teste " $\mathrm{t}$ ". $\mathrm{CV}=9,22$ 
Hydrodrip II 2,3 $\mathrm{L} \mathrm{h}^{-1}$ a $0,30 \mathrm{~m}\left(\mathrm{~L}_{6}\right)$ foram superiores às demais, sendo a Chapin $\left(\mathrm{L}_{8}\right)$ proporcionando o menor desenvolvimento vegetativo; entretanto, aos 45 dias o desenvolvimento das plantas, medido pela largura de faixa de solo coberto pelas plantas, mostrou-se semelhante entre as linhas de gotejadores (Fig. 1A).

Observa-se, entre as densidades de plantio, que as curvas de crescimento de plantas de melão foram semelhantes, com desaceleração a partir do $38^{\circ}$ dia, atingindo cobertura plena da área aos 45 dias da semeadura (Fig. 1B).

\section{A. Linhas de gotejamento}

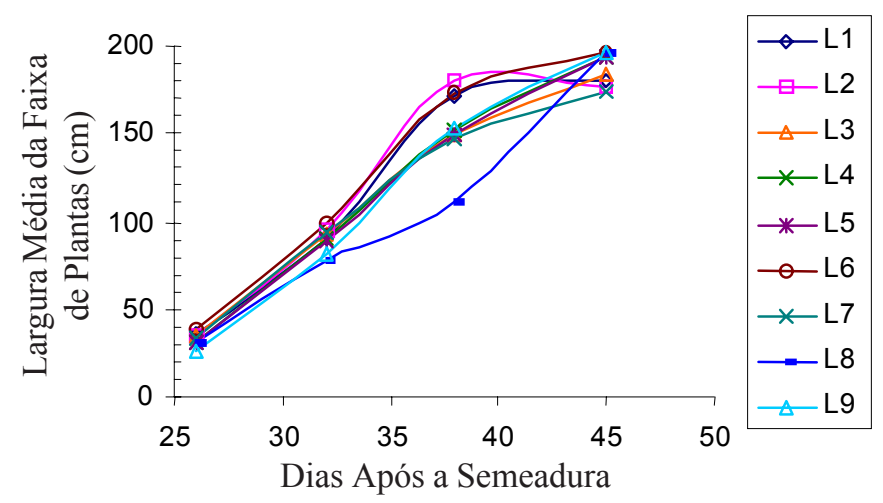

B. Densidade de plantas

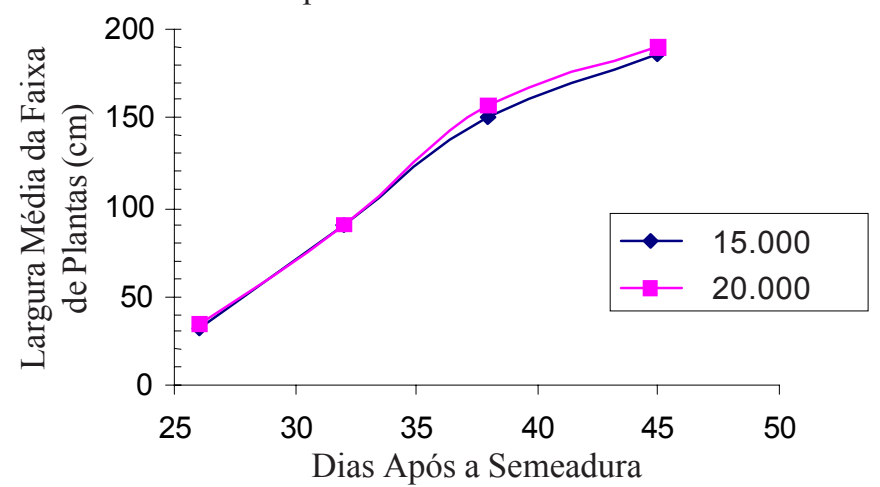

Figura 1. Crescimento das plantas de melão entre 26 e 45 dias após a semeadura. (A) Para as diferentes linhas de gotejadores; (B) em função das densidades de 15.000 e 20.000 plantas ha- ${ }^{-1}$

O peso médio de frutos totais foi afetado significativamente apenas para as linhas de gotejadores, indicando que a linha Hydrodrip II a $0,50 \mathrm{~m}\left(\mathrm{~L}_{5}\right)$ proporcionou frutos de peso médio superior aos da linha de gotejadores Netafima $0,50 \mathrm{~m}\left(\mathrm{~L}_{7}\right)$ que, por sua vez, não diferiu das demais linhas. O peso médio de frutos totais variou de 2,25 a $2,55 \mathrm{~kg}$, sendo comercialmente desejáveis para o consumidor nacional (Tabela 3 ).

Observou-se que o número total de frutos por planta decresceu com o aumento da densidade de plantio para as
Tabela 3. Pesos médios de frutos comerciais (PMFC) e da produção total (PMFT) e número total de frutos por planta (NTFP)

\begin{tabular}{ccc}
\hline Linha de & \multicolumn{2}{c}{ Variáveis* $^{*}(\mathrm{~kg})$} \\
\cline { 2 - 3 } Gotejadores & PFMC & PMFT \\
\hline L1 & $2,42 \mathrm{~A}$ & $2,32 \mathrm{AB}$ \\
L2 & $2,53 \mathrm{~A}$ & $2,41 \mathrm{AB}$ \\
L3 & $2,53 \mathrm{~A}$ & $2,41 \mathrm{AB}$ \\
L4 & $2,59 \mathrm{~A}$ & $2,53 \mathrm{AB}$ \\
L5 & $2,62 \mathrm{~A}$ & $2,55 \mathrm{~A}$ \\
L6 & $2,63 \mathrm{~A}$ & $2,50 \mathrm{AB}$ \\
L7 & $2,24 \mathrm{~A}$ & $2,25 \mathrm{~B}$ \\
L8 & $2,39 \mathrm{~A}$ & $2,26 \mathrm{AB}$ \\
L9 & $2,55 \mathrm{~A}$ & $2,49 \mathrm{AB}$ \\
\hline
\end{tabular}

* Médias seguidas pela letra maiúscula em cada coluna, não diferem a $5 \%$ de probabilidade, pelo teste Tukey. $\mathrm{CV}=9,5 \%$ e 7,3\%, respectivamente, para PFMC e PMFT

linhas de gotejadores Katif 2,3 $\mathrm{L} \mathrm{h}^{-1}$ a $0,60 \mathrm{~m}\left(\mathrm{~L}_{3}\right)$, Katif 3,75 $\mathrm{L} \mathrm{h}^{-1}$ a $0,60 \mathrm{~m}\left(\mathrm{~L}_{2}\right)$, Chapin a $0,30 \mathrm{~m}\left(\mathrm{~L}_{8}\right)$ e Queen gil a $0,30 \mathrm{~m}\left(\mathrm{~L}_{9}\right)$ registrando-se maior decréscimo para $\mathrm{L}_{8}(\mathrm{em}$ torno de $46,89 \%$ ) enquanto para o gotejador Hydrodrip II a $0,30 \mathrm{~m}\left(\mathrm{~L}_{6}\right)$ o aumento da densidade de plantio elevou o número de frutos por planta em torno de $34,15 \%$ (Tabela 4).

Geralmente, espera-se a obtenção de menor número de frutos por planta com o aumento da densidade de plantio, em conseqüência do menor espaço disponível às plantas, o que favorece a maior competição por elementos do solo e luz diminuindo, assim, a atividade fotossintética, a produção de ramos, folhas, flores e frutos e o trabalho das abelhas no processo de polinização, ocasionando reduções de número de frutos por planta (Grangeiro, 1997). Nem todos os tratamentos aplicados neste trabalho refletem tal relacionamento clássico entre a densidade de plantio e o número de frutos por planta, o que pode estar associado ao tipo de cultivar utilizada neste experimento, pois Grangeiro (1997) trabalhando com as cultivares Gold Mine, AF 646 e XPH 13096, observou que a cultivar "Gold Mine" foi a que apresentou menor decréscimo no número de frutos por planta, com o aumento da densidade, indicando ser esta menos susceptível às pressões de competição entre as plantas, com relação à diminuição do rendimento individual da planta.

Verificou-se que a produção total de melão diminuiu com o aumento da densidade de plantio apenas para a linha de gotejadores Chapin a $0,30 \mathrm{~m}\left(\mathrm{~L}_{8}\right)$, que apresentou menor rendimento (Tabela 5A). O incremento observado no aumento da produção de melão, quando se comparou a elevação da população de 15.000 para 20.000 plantas ha $^{-1}$, está em torno de $5,89 \%$, equivalente a um ganho de $1,31 \mathrm{Mg} \mathrm{ha}^{-1}$, cujos resultados corroboram com os obtidos por Paris et al. (1988) e Mendlinger (1994) em melão Galia. Nesses trabalhos, a densidade de 20.000 plantas ha $\mathrm{a}^{-1}$ foi a que proporcionou maior rendimento da cultura, a partir da qual ocorreu redução significativa no rendimento, que

Tabela 4. Número total de frutos por planta, em função das diferentes linhas de gotejadores

\begin{tabular}{|c|c|c|c|c|c|c|c|c|c|c|}
\hline \multirow{2}{*}{ Densidades } & \multicolumn{10}{|c|}{ Linha de Gotejadores* } \\
\hline & $\mathrm{L}_{1}$ & $\mathrm{~L}_{2}$ & $\mathrm{~L}_{3}$ & $\mathrm{~L}_{4}$ & $\mathrm{~L}_{5}$ & $\mathrm{~L}_{6}$ & $\mathrm{~L}_{7}$ & $\mathrm{~L}_{8}$ & $\mathrm{~L}_{9}$ & Média \\
\hline 15000 & $0,66 \mathrm{~A}$ & $0,82 \mathrm{~A}$ & $0,77 \mathrm{~A}$ & $0,65 \mathrm{~A}$ & $0,60 \mathrm{~A}$ & $0,64 \mathrm{~B}$ & $0,61 \mathrm{~A}$ & $0,59 \mathrm{~A}$ & $0,99 \mathrm{~A}$ & 0,70 \\
\hline 20000 & $0,63 \mathrm{~A}$ & $0,62 \mathrm{~B}$ & $0,52 \mathrm{~B}$ & $0,59 \mathrm{~A}$ & $0,43 \mathrm{~A}$ & $0,86 \mathrm{~A}$ & $0,55 \mathrm{~A}$ & $0,31 \mathrm{~B}$ & $0,73 \mathrm{~B}$ & 0,58 \\
\hline Média & 0,64 & 0,72 & 0,64 & 0,62 & 0,52 & 0,75 & 0,58 & 0,45 & 0,87 & \\
\hline
\end{tabular}


Tabela 5. Produção total e comercial de melão $\left(\mathrm{Mg} \mathrm{ha}^{-1}\right)$ em função das diferentes linhas de gotejadores e densidades de plantio

\begin{tabular}{|c|c|c|c|c|c|c|c|c|c|c|}
\hline \multirow{2}{*}{ Densidade } & \multicolumn{10}{|c|}{ Linhas de Gotejadores* } \\
\hline & $\mathrm{L}_{1}$ & $\mathrm{~L}_{2}$ & $\mathrm{~L}_{3}$ & $\mathrm{~L}_{4}$ & $\mathrm{~L}_{5}$ & $\mathrm{~L}_{6}$ & $\mathrm{~L}_{7}$ & $\mathrm{~L}_{8}$ & $\mathrm{~L}_{9}$ & Média \\
\hline \multicolumn{11}{|c|}{ A. Produção total } \\
\hline 20000 & $28,29 \mathrm{~A}$ & $29,53 \mathrm{~A}$ & $24,22 \mathrm{~A}$ & $29,68 \mathrm{~A}$ & $21,83 \mathrm{~A}$ & $41,78 \mathrm{~A}$ & $24,33 \mathrm{~A}$ & $12,58 \mathrm{~B}$ & $36,42 \mathrm{~A}$ & 27,63 \\
\hline Média & 25,64 & 29,82 & 25,61 & 27,49 & 22,91 & 33,27 & 22,58 & 17,85 & 35,63 & \\
\hline \multicolumn{11}{|c|}{ B. Produção comercial } \\
\hline 20000 & $27,08 \mathrm{~A}$ & $24,29 \mathrm{~A}$ & $19,35 \mathrm{~A}$ & $26,42 \mathrm{~A}$ & $18,19 \mathrm{~A}$ & $34,24 \mathrm{~A}$ & $18,98 \mathrm{~A}$ & $11,53 \mathrm{~A}$ & $31,62 \mathrm{~A}$ & 23,52 \\
\hline Média & 23,70 & 25,30 & 20,94 & 23,88 & 19,16 & 27,40 & 18,80 & 15,40 & 31,19 & \\
\hline
\end{tabular}

é crescente até determinada população; a partir daí, há decréscimo na produção, a medida em que se aumenta a população de plantas. Ainda em relação à Tabela $5 \mathrm{~A}$, a produção total de melão variou com os efeitos das diferentes linhas de gotejadores, tendo a Chapin a $0,30 \mathrm{~m}\left(\mathrm{~L}_{8}\right)$ produzido apenas $17,85 \mathrm{Mg} \mathrm{ha}^{-1}$, sendo significativamente inferior à obtida pelo gotejador Queen gil a $0,30 \mathrm{~m}\left(\mathrm{~L}_{9}\right)$ e Hidrodrip II a $0,30 \mathrm{~m}\left(\mathrm{~L}_{6}\right)$ que apresentaram maiores produções totais $\left(35,63 \mathrm{Mg} \mathrm{ha}^{-1} \mathrm{e}\right.$ 33,27 $\mathrm{Mg} \mathrm{ha}^{-1}$, respectivamente). Este fato se deve principalmente ao maior número total de frutos por planta, produzidos pela linha de gotejador Queen Gil a 0,30 m $\left(\mathrm{L}_{9}\right)$ e Hidrodrip II a $0,30 \mathrm{~m}\left(\mathrm{~L}_{6}\right)$, mesmo apresentando peso médio menor.

Observou-se, que para a linha de gotejadores Hydrodrip II a $0,30 \mathrm{~m}$ houve aumento da produção comercial de frutos quando se elevou a densidade de plantio, mas para as demais linhas, não ocorreu diferença estatística entre as populações de plantio para a produção comercial de frutos (Tabela 5B). Os valores médios da produção comercial de melão variaram de 15,40 a $31,19 \mathrm{Mg} \mathrm{ha}^{-1}$ e o incremento observado no aumento da produção comercial de melão, quando se compara o aumento da população, de 15.000 para 20.000 plantas ha-1, está em torno de $5,89 \%$, equivalente a um ganho de apenas $1,31 \mathrm{Mg} \mathrm{ha}^{-1}$. A produção comercial de melão foi, em média, inferior a 4,54\% em relação à produção total, equivalente a uma perda de 3,9 $\mathrm{Mg} \mathrm{ha}^{-1}$.

A linha de gotejadores que proporcionou menor rendimento $\left(\mathrm{L}_{8}\right)$ foi a que apresentou menor coeficiente de uniformidade de vazão (92\%) significativamente menor do que os demais, que apresentaram coeficiente de 95\% (Dias, 1998).

Para a textura dos frutos e sólidos solúveis totais não se constatou efeito significativo dos fatores estudados apresentando, em média, valores de $9,77^{\circ}$ Brix e textura de $29,64 \mathrm{~N}$.

\section{CONCLUSÕES}

1. O uso das linhas de gotejadores de menor espaçamento ou maior vazão e a maior densidade de plantio, proporcionaram maior porcentagem do stand de plantas de melão.

2. A elevação da densidade de plantio aumentou a produção comercial de frutos de melão apenas quando se utilizou a linha de gotejadores Hydrodrip II 2,3 $\mathrm{L} \mathrm{h}^{-1}$ a $0,30 \mathrm{~m}$.

3. A produção total de melão diminuiu com o aumento da densidade de plantio apenas para a linha de gotejadores Chapin $15 \mathrm{Mil} 1,12 \mathrm{~L} \mathrm{~h}^{-1}$ a $0,30 \mathrm{~m}$, que apresentou menor rendimento.
4. Maiores rendimentos de melão foram obtidos quando se utilizaram as linhas de gotejadores Queen gil 1,42 $\mathrm{L} \mathrm{h}^{-1} \mathrm{a}$ $0,30 \mathrm{~m}$ e Hydrodrip II 2,3 $\mathrm{L} \mathrm{h}^{-1}$ a $0,30 \mathrm{~m}$, porém foram significativamente superiores apenas em relação à linha de gotejadores Chapin $1,12 \mathrm{~L} \mathrm{~h}^{-1}$ a $0,30 \mathrm{~m}$.

5. A qualidade dos frutos não foi afetada pelos fatores estudados apresentando, em média, valores de 9,77 ${ }^{\circ}$ Brix e textura de $29,64 \mathrm{~N}$.

\section{REFERÊNCIAS BIBLIOGRÁFICAS}

ALMEIDA, J.H.S. Sistema de produção de melão cultivar valenciano amarelo para o estado do Rio Grande do Norte. Mossoró: ESAM, 1992, 45p. Monografia de Graduação.

BERNARDO, S. Manual de irrigação. 5. ed. Viçosa: Imprensa Universitária, 1995. 596p.

BEZERRA, L. Efeito de espaçamento e níveis de nitrogênio na produção e qualidade do melão. Revista Brasileira de Fruticultura, Recife, v.3, p.6-10, 1981.

DASBERG, S.; BRESLER, E. Drip irrigation manual. 9. ed. Israel: International Irrigation Information Center, 1985. 95p.

DIAS, N. da S. Avaliação de diferentes tipos e espaçamentos de gotejadores usados no cultivo de melão, semeado em faixa contínua, sub duas densidades de plantio. Mossoró: ESAM, 1998. 50p. Monografia de Graduação

FERREIRA, J.A. da S. Monitoramento da eficiência hídrica do meloeiro com termometria infravermelha. UFPB: Campina Grande, 1995, 52p. Dissertação de Mestrado.

GOMES, H.P. Engenharia de irrigação: Hidráulica dos sistemas pressurizados, aspersão e gotejamento. 3. ed. Campina Grande: Universidade Federal da Paraíba, 1999. 412p.

GOMES, P.F. Curso de estatística experimental. São Paulo: Nobel, 1987.

GRANGEIRO, L.C. Densidade de plantio em híbridos do melão amarelo. Mossoró: ESAM, 1997. 48p. Dissertação Mestrado

HOWELL. T.A.; HILLER, C.A. Trickle irrigation lateral design. Transactions of the ASAE, v.17, p.902-908, 1974.

JANICK, J. Competição biológica. In: A ciência da horticultura. Rio de Janeiro: USAID, 1968. Cap. 3, p.277-286.

MENDLINGER, S. Effect of increasing plant density and salinity on yield and fruit quality in muskmelon. Scientia Horticulturae, v.57, p.41-49, 1994. 
PARIS, H.S.; NERSON, H.; BURGER, Y.; EDELSTEIN, M.; KARCHI, Z. Synchrony of yield of melons as affected by plant type and density. Journal of Horticultural Science, Alexandria, v.63, n.1, p.300-301, 1988.

PEDROSA, J.F. Cultura do melão em Mossoró: ESAM, 1997. 50p. Apostila.

ROBINSON, R.W.; DECKER-WALTERS, D.S. Cucurbits. New York: CAB Internacional, 1997.226p.
SCALOPPI, E. J. Critérios básicos para seleção de sistemas de irrigação. Informe Agropecuário, Belo Horizonte, v.2, n.139, p.54-63, 1986.

SUDENE - Superintendência do Desenvolvimento do Nordeste, Divisão Agrologia Mapa Exploratório - Reconhecimento de solos do Estado do Rio Grande do Norte. Mapa ed. 75 x 85 $\mathrm{cm}$, Escala 1:500 000, 1968.

VERMEIREN, L.; JOBLING, G.A. Riego localizado. Roma: FAO, 1986.203p. 